\title{
Effect of Nutritional Support on Treatment of Multi-Drug Resistant Tuberculosis in Rajshahi Division, Bangladesh
}

\author{
Md. Abu Sayem¹, Md. Golam Hossain², Tahmeed Ahmed ${ }^{3}$, Khaled Hossain ${ }^{4}$, Zahangir Alam Saud4* \\ ${ }^{1}$ Institute of Biological Sciences, University of Rajshahi, Rajshahi, Bangladesh \\ ${ }^{2}$ Department of Statistics, University of Rajshahi, Rajshahi, Bangladesh \\ ${ }^{3}$ Department of Public Health, James P. Grant School of Public Health, Dhaka, Bangladesh \\ ${ }^{4}$ Department of Biochemistry and Molecular Biology, University of Rajshahi, Rajshahi, Bangladesh \\ Email: *zasaud@ru.ac.bd
}

How to cite this paper: Sayem, Md.A., Hossain, Md.G., Ahmed, T., Hossain, K. and Saud, Z.A. (2020) Effect of Nutritional Support on Treatment of Multi-Drug Resistant Tuberculosis in Rajshahi Division, Bangladesh. Journal of Tuberculosis Research, 8, 223-236.

https://doi.org/10.4236/jtr.2020.84020

Received: October 25, 2020

Accepted: December 28, 2020

Published: December 31, 2020

Copyright (c) 2020 by author(s) and Scientific Research Publishing Inc. This work is licensed under the Creative Commons Attribution International License (CC BY 4.0).

http://creativecommons.org/licenses/by/4.0/

\begin{abstract}
Introduction: Multi-drug resistant tuberculosis (MDR-TB) is a public health crisis throughout the world including Bangladesh particularly due to its complexities in diagnosis, longer treatment regimen, and adverse drug reaction. Nutritional supplementation has significant impact on patient's weigh gain and optimum weight gain is a biomarker of treatment response. The objective of this study was to measure body mass index (BMI) progress among MDR-TB patients in different phases of treatment. Methodology: A prospective observational study was conducted from March 2010 to July 2015 in Chest Disease Hospital (CDH), Rajshahi and different communities of Rajshahi Division, Bangladesh. A total of 233 confirmed MDR-TB patients were selected from $\mathrm{CDH}$ who received treatment and nutritional support from ongoing national TB control program (NTP). They received free diagnosis, follow up tests, treatment and nutritional support as regular diet as well as cash amount Bangladeshi taka (BDT.) 1000 per month in CDH. Along with treatment, they also received only cash amount BDT. 1500 per month as nutritional support at community level. Weight measurement was taken at regular interval from enrollment to completion of treatment. Chi-square, paired t-test and linear regression analysis were used in this study. Results: The baseline prevalence of undernourished (BMI $<18.5 \mathrm{~kg} / \mathrm{m}^{2}$ ) was $82.4 \%$. After two months of treatment, $14.5 \%$ underweight patients gained weight and reverted to normal BMI. Regression analysis showed the decreasing tendency of BMI progress with increasing age which was significant among male patients $(\mathrm{p}<0.05)$. We observed reversely that patients gained more BMI in intensive phase than continuation phase of treatment. The cohort results demonstrated that the
\end{abstract}


treatment success rate was lower $(<83 \%)$ among initially underweight patients than their counterparts $(>92 \%)$. Conclusion: Nutritional support has synergistic effect on treatment response. Adequate nutritional support with proper treatment would help to get better outcomes particularly at community level. Gender issue should also be addressed at household level.

\section{Keywords}

Bangladesh, BMI Progress, MDR-TB, Nutritional Support

\section{Introduction}

Multi-drug resistant tuberculosis (MDR-TB) is a major obstacle for TB control due to difficulties in diagnosis, longer treatment regimen and more adverse drug reaction [1] [2]. The drug susceptible tuberculosis (DS-TB) is the main source of MDR-TB due to irregular or inadequate treatment following poor adherence, supply interruption or physicians error or treated with wrong drugs [3] [4]. Along with cough, fever and anorexia, weight loss is a major feature of both TB and MDR-TB [3] [5] [6]. A MDR-TB patient usually faces more loss of appetite which causes more weight loss [3] [5]. A marked under nutrition is an identified risk factor for TB related mortality [7] [8]. Studies perceived that malnourished are more prone to develop TB and they are more likely to have advanced disease and greater risk of side effects and deaths compared to patients with normal BMI [9] [10]. There is synergistic relationship between TB and malnutrition adversely impact of each other [11] [12]. Weight gain over time during treatment can be a biomarker of treatment effectiveness and better treatment outcomes [3] [8]. It is a simple and less expensive but valuable tool for patient management. The early screening of malnutrition and nutritional supplementation can effectively response to treatment and rapid recovery from disease [13] [14]. Study suggests that along with treatment, supplementation of nutrition particularly among malnourished patients (BMI $<18.5 \mathrm{~kg} / \mathrm{m}^{2}$ ) with dietary counseling would be a good practice [15]. The correction of malnutrition can reduce suffering, costs, and deaths and increase weight [16]. In Bangladesh, poverty, population density and malnutrition are common which reduces productivity in adults, increases susceptibility to infection, and decelerates recovery from illness [17] [18]. In addition, malnutrition enhances the reactivation of TB disease, and conversely, patients become malnourished when they contract the disease [18] [19] [20]. Bangladesh ranks $6^{\text {th }}$ among 22 high DS-TB and $9^{\text {th }}$ among 25 high MDR-TB burden countries [3] [21] [22]. Bangladesh National Tuberculosis Control Program (NTP) is providing nationwide free diagnostic and treatment support and other necessary support including nutritional support to MDR-TB patients under programmatic management of drug resistant TB (PMDT) [5]. However, once diagnosed as MDR-TB in north-west belt of Bangladesh, patients were admitted to Chest Disease Hospital (CDH), Rajshahi. They stayed for a full period 
of intensive phase of treatment. After completion of four months intensive phase, they moved to the community to continue the continuation phase of treatment under PMDT following discharge criteria. It is noted that MDR-TB patients were receiving food and financial support in both hospital and the community through PMDT. The purpose of this study was to evaluate the effect of nutritional support at different phases of treatment.

\section{Methodology}

\subsection{Study Design and Site}

An observational prospective study was conducted at Chest Disease Hospital (CDH), Rajshahi and at home level during March 2010 to July 2015. Two hundred and thirty three confirmed adult MDR-TB patients were included in the study. The study purpose was shared and informed consent was taken from each respondent. After completion of measurement and other relevant data, we waited for additional fifteen months to get treatment outcomes report as cohort results.

\subsection{Inclusion Criteria}

Out of 340 registered MDR-TB patients at CDH under PMDT, 233 patients (68\%) were selected for this study who had a complete cohort record. Finally, we analyzed BMI progress of 187 patients (55\%) who had regular weight records from the beginning to the end of treatment.

\subsection{Exclusion Criteria}

Patients were excluded from the study if: 1) transfer out, 2) a major defaulter within one month, 3) primarily detected mono and poly drug resistant $\mathrm{TB}, 4$ ) Drug susceptible TB cases and 5) Patient below 15 years old. For BMI, the rest of patients were excluded for their irregular weight records and residence other than Rajshahi Division. HIV status was unknown. We assessed the effect of nutritional support to adult MDR-TB patients on the basis of BMI variation with treatment and food support at regular interval started from hospital and ended to community. In this study, the optimum BMI gain indicates the treatment effectiveness as well as nutritional effect. The gradual BMI gain indicates the recovery process from disease with adequate nutrition. Static BMI indicates recovery process with improper nutrition and decreasing BMI indicates unidentified co-morbidity with improper nutrition or disease with other confounding factors.

\subsection{Study Setting}

Under the NTP, a special program named as programmatic management of drug resistant TB (PMDT) through which NTP is providing nutritional support to MDR-TB patients at both hospital and community level. The nutritional support was a provision of lunch and dinner at $\mathrm{CDH}$, which comprised of rice vegetables, meat/fish, and lentil soup. In addition, patients received an egg, $250 \mathrm{ml}$ 
milk/one banana and pieces of bread as breakfast in the intensive phase of treatment at hospital. Along with free food, diagnosis, follow up tests and treatment, cash support of BDT. 1000 (about US Dollar 12) per month was provided to buy additional food as per patient's choice up to four months of intensive phase. Only the weight progress was measured during the treatment period in different settings and no additional nutritional support was added. However, when the patients moved to the community, based on discharge criteria, BDT. 1500 was given monthly for purchasing food as nutritional support up to completion of treatment under PMDT. In our study area, nine months treatment regimen with four months intensive and five months continuation phases was followed. It is noted that NTP was following 20 to 22 months of treatment regimen for MDR-TB throughout the country except CDH Rajshahi and few other facilities collaborated with non-government organization (NGO)-Damien Foundation [5].

\subsection{Data Collection}

Socio-demographic and anthropometric data were collected by trained data collectors. The height and weight records were collected during enrollment and subsequently weight was taken monthly up to nine months. All treatment outcomes were collected from the prescribed format and registers of $\mathrm{CDH}$.

\subsection{Outcome Variable}

BMI was considered as outcome variable which was calculated from height and weight using the formula, BMI = weight in $(\mathrm{kg}) /$ height in (meter) ${ }^{2}$. According to WHO standard, four categories of BMI-underweight (BMI $<18.5 \mathrm{~kg} / \mathrm{m}^{2}$ ), normal $\left(18.5 \leq \mathrm{BMI}<25 \mathrm{~kg} / \mathrm{m}^{2}\right)$, overweight $\left(25 \leq \mathrm{BMI}<30 \mathrm{~kg} / \mathrm{m}^{2}\right)$ and obese (BMI $\left.\geq 30 \mathrm{~kg} / \mathrm{m}^{2}\right)$ was followed [23].

\subsection{Statistical Analysis}

Data were analyzed using Statistical Package for Social Sciences (SPSS, IBM version 23) software. Chi-square test was used to find out the association between two categorical variables. As outcome variables (BMI) were normally distributed, paired sample t-test was utilized to see the difference between two phases of treatment and linear regression analysis was performed to measure the weight gain over time according to gender. The $\mathrm{p}$-value $<0.05$ was considered as statistically significant.

\section{Results}

Out of 233 respondents for treatment outcomes, 187 patients were eligible for BMI analysis (Figure S1). During enrollment, $82.4 \%$ patients were underweight and the mean BMI was $16.56 \mathrm{~kg} / \mathrm{m}^{2}$. More than $71 \%$ were male patients. Most of the patients (72\%) were young age (16 - 37 years) group. The overall treatment success rate was $84.1 \%$. The treatment success rate is the positive treatment out- 
comes of combination of cured and treatment completed. A patient is considered as cured when he or she completed treatment according to NTP protocol without evidence of treatment failure and three consecutive sputum cultures are negative with clinical improvement [5]. Subsequently, the technical term treatment completed means the person who completed treatment following NTP protocol but fails to meet the definition of cure due to lack of bacteriological results [5]. In this study, the treatment success rate was also lower among initially underweight patients (82.3\%) than normal and overweight patients (92.6\%) (Table 1). Alternatively, the unsuccessful outcomes such as loss to follow up, death and treatment failure were higher among initially underweight (BMI < $18.5)$ patients $(7.8 \%, 8.9 \%, 1.0 \%)$ respectively. The term treatment failure of

Table 1. Age and gender distribution according to BMI and treatment outcomes analysis.

\begin{tabular}{|c|c|}
\hline Age group & $\mathrm{N}(\%), \mathrm{n}=187$ \\
\hline $16-26$ & $79(42.2)$ \\
\hline $27-37$ & $56(29.9)$ \\
\hline $38-48$ & $26(13.9)$ \\
\hline$\geq 49$ & $26(13.9)$ \\
\hline \multicolumn{2}{|l|}{ Gender } \\
\hline Male & $133(71.1)$ \\
\hline Female & $54(28.9)$ \\
\hline Overall Treatment outcomes (TO) & $\mathrm{N}(\%), \mathrm{n}=233$ \\
\hline Treatment completed & $4(1.7)$ \\
\hline Cured & $192(82.4)$ \\
\hline Loss to follow up & $16(6.9)$ \\
\hline Died & $19(8.2)$ \\
\hline Treatment Failure & $2(0.9)$ \\
\hline TO among underweight patient & $\mathrm{N}(\%), \mathrm{n}=192$ \\
\hline Treatment completed & $3(1.6)$ \\
\hline Cured & $155(80.7)$ \\
\hline Loss to follow up & $15(7.8)$ \\
\hline Died & $17(8.9)$ \\
\hline Treatment Failure & $2(1.0)$ \\
\hline TO among normal, over weight and obese patient & $\mathrm{N}(\%), \mathrm{n}=41$ \\
\hline Treatment completed & $1(2.4)$ \\
\hline Cured & $37(90.2)$ \\
\hline Loss to follow up & $1(2.4)$ \\
\hline Died & $2(4.9)$ \\
\hline Treatment Failure & $0(0.0)$ \\
\hline
\end{tabular}

(N: number of patient, there was no "not evaluated and transfer out cases" for outcomes). 
MDR-TB depends on follow up tests results. If the sputum is still positive for bacilli in continuation phase (non-conversion) or bacteriological reversion (negative to positive) in continuation phase or evidence of resistance to fluoroquinolones and second line injectable anti-TB drugs are usually considered as treatment failure [5]. The other technical terms are properly described in national PMDT guidelines [5].

After two months of treatment, underweight reduced from 154 (82.4\%) to 127 (67.9\%). Chi-square test $\left(\chi^{2}\right)$ revealed that the underweight reduction rate was higher among male (65.4\%) than females (74.1\%). Finally, 57 (30.5\%) underweight patients gained normal BMI at month nine (Table 2).

The increasing tendency of mean BMI with respect to times was observed and the monthly variation in BMI was explained by $95.2 \%$ using polynomial of degree two models (Figure 1). The linear regression analysis demonstrated that the progress of BMI was significantly $(\mathrm{p}<0.05)$ declined with increased age among male patients ( $95 \% \mathrm{CI}-0.036$ to -0.003 ) and among female MDR-TB patients, the BMI progress was also declined with increased age which was not significant (95\% CI -0.040 to 0.034$)(\mathrm{p}>0.05)$ (Table 3$)$.

Table 2. Body mass index (BMI) changes over time according to gender.

\begin{tabular}{|c|c|c|c|c|c|c|}
\hline Gender & BMI category & $\begin{array}{l}\text { Number of } \\
\text { patient (\%) }\end{array}$ & $\begin{array}{c}\text { N.P after two } \\
\text { months of tr. (\%) }\end{array}$ & $\begin{array}{c}\text { N.P after four } \\
\text { months of tr. (\%) }\end{array}$ & $\begin{array}{c}\text { N.P after six } \\
\text { months of tr. (\%) }\end{array}$ & $\begin{array}{c}\text { N.P after nine months } \\
\text { of } \operatorname{tr} .(\%)\end{array}$ \\
\hline \multirow{4}{*}{$\begin{array}{c}\text { Male } \\
\text { MDR-TB }\end{array}$} & Underweight & 109 (81.9) & $87(65.4)$ & 77 (57.9) & $77(57.9)$ & $62(46.6)$ \\
\hline & Normal & $23(17.3)$ & $45(33.8)$ & $54(40.6)$ & $54(40.6)$ & $67(50.4)$ \\
\hline & Overweight & $1(0.8)$ & $1(0.8)$ & $2(1.5)$ & $1(0.8)$ & $4(3.0)$ \\
\hline & Obese & $0(0.0)$ & $0(0.0)$ & $0(0.0)$ & $1(0.8)$ & $0(0.0)$ \\
\hline \multirow{4}{*}{$\begin{array}{l}\text { Female } \\
\text { MDR-TB }\end{array}$} & Underweight & $45(83.3)$ & $40(74.1)$ & $38(70.4)$ & $41(75.9)$ & $35(64.8)$ \\
\hline & Normal & 09 (16.7) & $14(25.9)$ & $16(29.6)$ & $13(24.1)$ & $19(35.2)$ \\
\hline & Overweight & $0(0.0)$ & $0(0.0)$ & $0(0.0)$ & $0(0.0)$ & $0(0.0)$ \\
\hline & Obese & $0(0.0)$ & $0(0.0)$ & $0(0.0)$ & $0(0.0)$ & $0(0.0)$ \\
\hline
\end{tabular}

(N.P: Number of Patient; tr.: treatment).

Table 3. BMI $\left(\mathrm{kg} / \mathrm{m}^{2}\right)$ progress with age of respondents (regression analysis).

\begin{tabular}{|c|c|c|c|c|c|c|c|}
\hline \multicolumn{8}{|c|}{ Progress of BMI $\left(\mathrm{kg} / \mathrm{m}^{2}\right)$ among MDR-TB with patient's age } \\
\hline \multirow{4}{*}{ Total } & \multirow{2}{*}{ Variable } & \multirow{2}{*}{ Coefficient (B) } & \multirow{2}{*}{ SE } & \multirow{2}{*}{ T-value } & \multirow{2}{*}{ P-value } & \multicolumn{2}{|c|}{$95.0 \% \mathrm{CI}$ for $\mathrm{B}$} \\
\hline & & & & & & Lower Bound & Upper Bound \\
\hline & Respondents' age & -0.018 & 0.007 & -2.408 & 0.017 & -0.033 & -0.003 \\
\hline & Constant & 2.480 & 0.263 & 9.443 & 0.000 & 1.962 & 2.998 \\
\hline \multirow{2}{*}{ Male } & Respondents' age & -0.019 & 0.009 & -2.275 & 0.025 & -0.036 & -0.003 \\
\hline & Constant & 2.495 & 0.318 & 7.842 & 0.000 & 1.866 & 3.125 \\
\hline \multirow{2}{*}{ Female } & Respondents' age & -0.003 & 0.018 & -0.152 & 0.880 & -0.040 & 0.034 \\
\hline & Constant & 2.140 & 0.546 & 3.921 & 0.000 & 1.045 & 3.234 \\
\hline
\end{tabular}




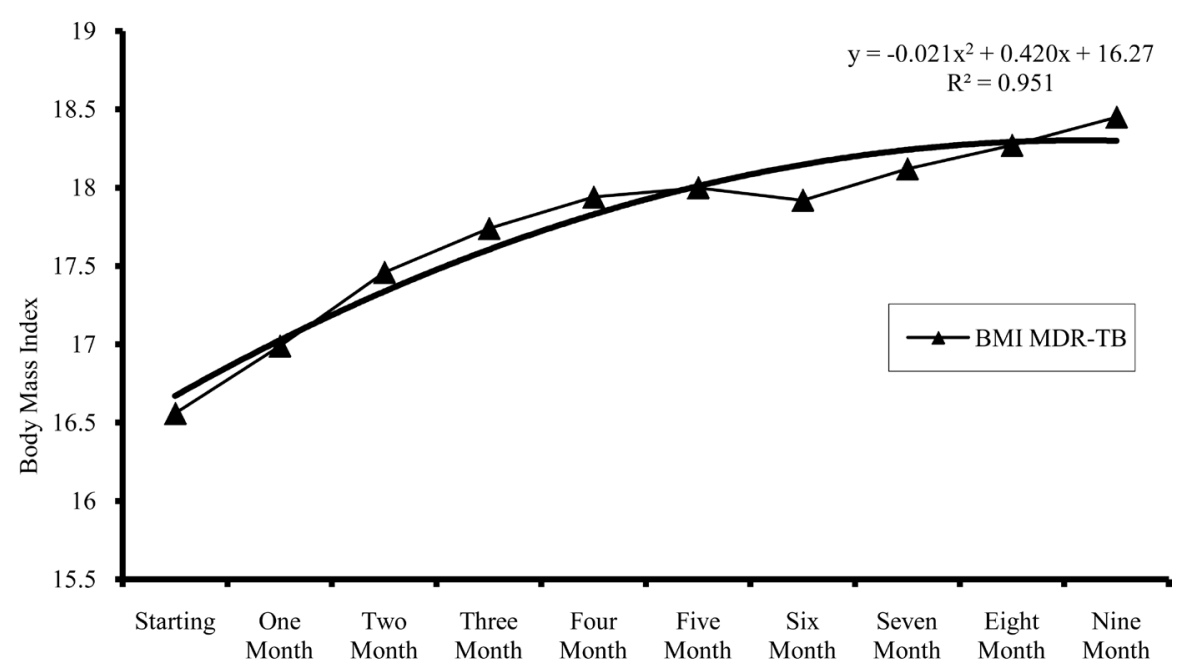

Figure 1. Trend of mean BMI progress among MDR-TB patients with treatment. A polynomial of degree two models among MDR-TB ( $n=187$, at 95.2\% level).

According to phases of treatment, the paired sample t-test clearly demonstrated the synergistic effect of nutritional support in intensive phase of treatment where rapid and maximum weight gain was observed. The mean weight gain in kilogram (kg.) with standard error (SE) was $(3.43 \pm 0.22)$ in intensive phase and $(1.23 \pm 0.12)$ in continuation phase of treatment which was mostly significant $(\mathrm{p}<0.001)$ (Figure 2$)$. The inadequate nutritional support was evident in continuation phase of treatment due to inadequate weight gain following recovery from disease.

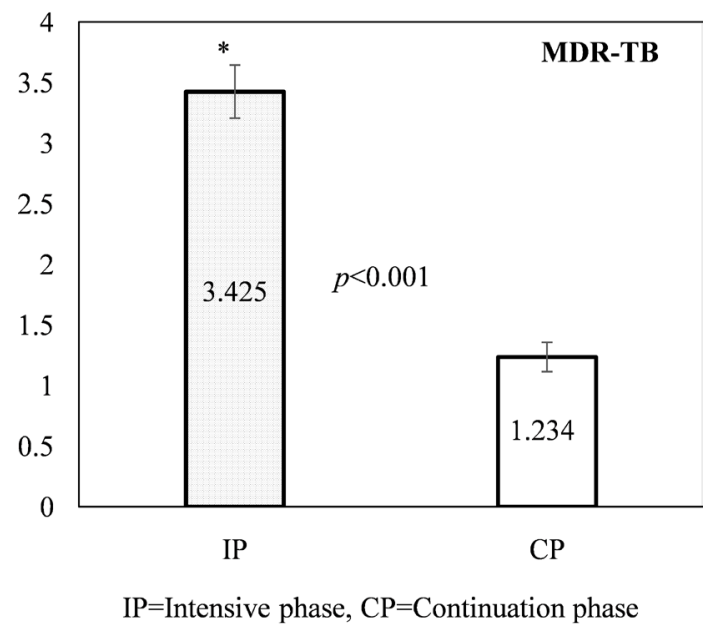

Figure 2. Mean weight gain in kilogram in different treatment phases. Mean weight gain of intensive phase (IP) and continuation Phase (CP) were expressed as Mean, where $\mathrm{n}=$ 187. ${ }^{*}$ Significantly different from intensive phase to continuation phase of treatment at $\mathrm{p}$ $<0.001$ in paired sample t-test.

\section{Discussion}

We evaluated the effect of nutritional support with treatment among MDR-TB patients which was expressed as weight gain over time. We also analyzed the 
adequacy and access to nutritional support as adjunctive therapy in different settings. In Bangladesh, NTP is providing nutritional support only to MDR-TB patient through PMDT. On the other hand, drug susceptible TB (DS-TB) patients are still left behind. However, we found that most underweight patient's age was within 16 to 37 years (72.1\%). The young age is a potential for work productivity which may cause development barrier for any country if they have malnutrition and MDR-TB. The cumulative financial losses due to disease and cost of treatment can slow down the economy of a country [24] [25]. We found that males were more prone to develop MDR-TB than females and the results of this study were consistent with previous study [25]. Several studies reported that poor treatment outcomes are predominant among MDR-TB, mostly as retreated cases and its success rate is lower than DS-TB [22] [26] [27] [28]. We also found lower treatment success rate among MDR-TB (84\%) compared to national DS-TB treatment success rate $(>95 \%)$ [29]. The term treatment success rate is the combination of both cured and treatment completed. The TB related technical terms such as cured, completed, failure, loss to follow up and others are properly described in WHO approved national guidelines and national PMDT guidelines [3] [5]. The unfavorable outcomes were higher among initially underweight patients (BMI < 18.5) (Table 1$)$. It indicates the necessity of extra care and supports for underweight patients from the beginning of treatment. In this study, we found that MDR-TB was mostly developed among those who had poor treatment adherence during DS-TB treatment. The results of our study were validated with previous studies [25] [26] [27] [28]. Like other studies, we also observed higher deaths among MDR-TB (8.2\%) than DS-TB [26] [28] [29]. However, the under-weight was more predominant (>81\%) among MDR-TB (Table 2). This might be due to the virulence of pathogen and the rapid loss of appetite. Several studies also stated that underweight is frequent among the MDR-TB patients $(68 \%$ to $75 \%)$ at baseline and they have a greater risk of deaths than normal weight [9] [26] [27]. In this study, patients received an adequate diet (three times a day) as well as financial support to purchase food as an individual's choice at hospital. Such kind of nutritional support, regular DOT and timely correction of adverse drug reaction (ADR) facilitated the rapid weight gain at $\mathrm{CDH}$. The weight gain with treatment indicates the recovery from disease. However, each patient did not gain similar weight, even a few patients losses weight for a certain time; most patients ultimately gained weight after four months of treatment.

Such weight gain indicates the synergistic effect of nutritional support on treatment effectiveness (Figure 2). A study reported that a modest weight gain with nutritional supplementation can be a predictor of better treatment outcomes [8]. Alternatively, the possible causes of suppression of weight gain or loss of weight in some patients might be due to unidentified co-morbidity or confounders or ADR. Other studies also validated our findings that negative predictor of weight gain is associated with malignancy or co-infection with diabetes, hepatitis [6] [14]. We observed that more weight gain occurs in first two months 
of treatment compared to next subsequent months. This might be due to more bactericidal effects of drugs as well as adequate and regular nutritional support at the initial stage. Subsequently, patients become stable and adjusted with treatment over time. Interestingly, male patients gained more weight in intensive phase. It may indicate higher treatment response which may due to different reproductive biology or drug tolerability that leads to less chance of unidentified co-morbidity or nutrient loss which interrupt the optimum weight gain. However, after completion of the intensive phase, despite providing monthly financial support for food with treatment at household level, under-weight did not adequately turn into normal weight; rather under-weight increased among female patients (Table 2). The result indicates that females were deprived to have adequate nutrition in their family. However, male patient's underweight was static, which also indicates improper food intake at the household level. Therefore, it is important to review the amount of money for nutritional support, its optimum utilization, culture and gender issues in the community. We observed that BMI progress was negatively influenced by age of patients and the trend of lower progress of BMI with increased age, particularly among males (Table 3). Interestingly, the tendency of lower progress of BMI was not significant among females, which may indicate different human biology, drug tolerability, and regularity in food habits and culture. Another study reported that the existing stigma hindering the treatment adherence thus may also contribute to develop MDR-TB [30]. Alternatively, adequate counseling can enhance treatment adherence [30]. Studies suggest that regular monitoring of DS-TB treatment and timely correction of ADR, advocacy to eliminate stigma, counseling and nutritional support with quality DOT would help prevent development of MDR-TB [5] [31] [32] [33] [34]. Though we expected the gradual improvement of BMI due to recovery from the disease over time, patients gained more weight in the intensive phase due to more nutrition intervention with quality DOT. Like our study, another study described that young are more physically active in their life through exposed to contact with patients and irregularity of treatment assuming to have the chance of developing MDR-TB [35]. Further study is needed to identify the other confounding factors on why and how young age groups are more vulnerable to develop MDR-TB.

\section{Limitation of the study}

In our study, HIV, diabetes, socio-economic condition, smoking and behavioral factors were not properly considered. The above mentioned areas may provide potential clues to the researcher for further study.

\section{Conclusion}

We found that nutritional support has the synergistic effect in gaining weight with recovery from disease. The more financial support to the MDR-TB patients particularly at community level would help achieve the expected gradual progress 
of weight gain. High quality DOT with nutritional support to DS-TB including special focus on the malnourished group would prevent resistant, transmission, death and other unfavorable outcomes. Social and behavioral changes are also needed to address the female patients.

\section{Acknowledgements}

Authors like to thank to authorities of CDH, NTP and UHCs and Damien Foundation in Rajshahi division for their support and cooperation.

\section{Author Contributions}

MAS and ZAS designed this study. MAS collected data from Hospital and different facilities in Rajshahi division. MAS, ZAS and MGH prepared and analyzed the data. TA, MMR, KH and ZAS revised this manuscript. All authors approved the final version.

\section{Ethics and Consent}

Ethical approval (No: 49/320/IAMEBBC/IBSC) for this study was taken from the Institutional Animal, Medical Ethics, Biosafety and Biosecurity Committee of Institute of Biological Sciences, University of Rajshahi, Bangladesh. Informed consent was taken from each participant.

\section{Funding Information}

This research did not receive any grant from funding organizations, agencies, institutions or from public or individual.

\section{Conflicts of Interest}

The authors declare no conflicts of interest regarding the publication of this paper.

\section{References}

[1] Banu, S., Rahman, M.T., Ahmed, S., et al. (2017) Multidrug-Resistant Tuberculosis in Bangladesh: Results from a Sentinel Surveillance System. The International Journal of Tuberculosis and Lung Disease, 21, 12-17.

https://doi.org/10.5588/ijtld.16.0384

[2] World Health Organization (2015) The End TB Strategy. WHO, Geneva. https://www.who.int/tb/post2015_strategy/en

[3] National Guidelines and Operational Manual for Tuberculosis Control. National Tuberculosis Control Program (NTP) (2013) Directorate General of Health Services (DGHS), Bangladesh, 5th Edition.

[4] Maharjan, S., Singh, A., Khanda, D.K. and Aryal, M. (2017) Drug Resistance Pattern in Pulmonary Tuberculosis Patients and Risk Factors Associated with Multidrug Resistant Tuberculosis. Journal of Tuberculosis Research, 5, 106-117. https://doi.org/10.4236/jtr.2017.52012

[5] National Guidelines and Operational Manual for Programmatic Management of 
Drug Resistant TB (PMDT) (2013) National Tuberculosis Control Program (NTP), Directorate General of Health Services (DGHS), Bangladesh, 2nd Edition.

[6] Pahan, M.N., Guy, E.S., Nickson, R.N. and Kao, C.C. (2016) Predictors and Pattern of Weight Gain during Treatment for Tuberculosis in the United States of America. International Journal of Infectious Diseases, 53, 1-5. https://doi.org/10.1016/j.ijid.2016.09.006

[7] Zachariah, R., Spielmann, M.P., Harries, A.D. and Salaniponi F.M. (2002) Moderate to Severe Malnutrition in Patients with Tuberculosis Is a Risk Factor Associated with Early Death. Transactions of the Royal Society of Tropical Medicine and Hygiene, 96, 291-294. https://doi.org/10.1016/S0035-9203(02)90103-3

[8] Chung-Delgado, K., Revilla-Montag, A., Guillen-Bravo, S. and Bernabe-Ortiz, A. (2014) Weight Variation over Time and Its Relevance among Multidrug-Resistant Tuberculosis Patients. The International Journal of Infectious Diseases, 23, 20-24. https://doi.org/10.1016/j.ijid.2014.01.001

[9] Gler, M.T., Guilatco, R., Caoili, J.C., Ershova, J., Cegielski, P. and Johnson, J.L. (2013) Weight Gain and Response to Treatment for Multidrug-Resistant Tuberculosis. The American Journal of Tropical Medicine and Hygiene, 89, 943-949. https://doi.org/10.4269/ajtmh.13-0011

[10] Baldwin, M.R., Yori, P.P., Ford, C., et al. (2004) Tuberculosis and Nutrition: Disease Perceptions and Health Seeking Behavior of Household Contacts in the Peruvian Amazon. The International Journal of Tuberculosis and Lung Disease, 8, 1484-1491.

[11] Hood, M.L.H. (2013) A Narrative Review of Recent Progress in Understanding the Relationship between Tuberculosis and Protein Energy Malnutrition. European Journal of Clinical Nutrition, 67, 1122-1128. https://doi.org/10.1038/ejcn.2013.143

[12] Padmapriyadarsini, C., Shobana, M., Lakshmi, M., Beena, T. and Swaminathan, S. (2016) Undernutrition and Tuberculosis in India: Situation Analysis \& the Way Forward. Indian Journal of Medical Research, 144, 11-20. https://doi.org/10.4103/0971-5916.193278

[13] Parande, M.A., Borle, P.S., Tapare, V.S., More, S.W. and Bhattacharya, S.S. (2018) Change in Body Weight and Treatment Outcome in Sputum Positive Pulmonary Tuberculosis Patients Treated under Directly Observed Treatment Short-Course. International Journal of Community Medicine and Public Health, 5, 2431-2436. https://doi.org/10.18203/2394-6040.ijcmph20182172

[14] Grobler, L., Nagpal, S., Sudarsanam, T.D. and Sinclair, D. (2016) Nutritional Supplements for People Being Treated for Active Tuberculosis. Cochrane Database of Systematic Reviews, 6, CD006086. https://doi.org/10.1002/14651858.CD006086.pub4

[15] Koethe, J.R. and Von Reyn, C.F. (2016) Protein-Calorie Malnutrition, Micronutrient Supplements, and Tuberculosis. The International Journal of Tuberculosis and Lung Disease, 20, 857-863. https://doi.org/10.5588/ijtld.15.0936

[16] Podewils, L.J., Holtz, T., Riekstina, V., et al. (2011) Impact of Malnutrition on Clinical Presentation, Clinical Course, and Mortality in MDR-TB Patients. Epidemiology \& Infection, 139, 113-120. https://doi.org/10.1017/S0950268810000907

[17] Demographic and Health Survey (2014) Bangladesh. https://microdata.worldbank.org/index.php/catalog/2562

[18] Kirpalani, S. (2016) Crowded House: Analyzing Overpopulation and Poverty in Bangladesh and Indonesia. Global Majority E-Journal, 7, 28-37.

[19] Van Lettow, M., Kumwenda, J.J., Harries, A.D., et al. (2004) Malnutrition and the Severity of Lung Disease in Adults with Pulmonary Tuberculosis in Malawi. The 
International Journal of Tuberculosis and Lung Disease, 8, 211-217.

[20] Onwubalili, J.K. (1988) Malnutrition among Tuberculosis Patients in Harrow, England. European Journal of Clinical Nutrition, 42, 363-366.

[21] National Tuberculosis Control Program (2016) Directorate General of Health Services (DGHS), Dhaka, Bangladesh. Annual Report 2016.

[22] Banu, S., Mahmud, A.M., Rahman, M.T., et al. (2012) Multidrug-Resistant Tuberculosis in Admitted Patients at a Tertiary Referral Hospital of Bangladesh. PLoS One, 7, e40545. https://doi.org/10.1371/journal.pone.0040545

[23] Subramanian, S.V., Perkins, J.M. and Khan, K.T. (2009) Do Burdens of Underweight and Overweight Coexist among Lower Socioeconomic Groups in India? The American Journal of Clinical Nutrition, 90, 369-376. https://doi.org/10.3945/ajcn.2009.27487

[24] Workicho, A., Kassahun, W. and Alemseged, F. (2017) Risk Factors for Multi-Drug Resistant Tuberculosis among Tuberculosis Patients: A Case-Control Study. Infection and Drug Resistance, 10, 91-96. https://doi.org/10.2147/IDR.S126274

[25] Rifat, M., Milton, A.H., Hall, J., et al. (2014) Development of Multidrug Resistant Tuberculosis in Bangladesh: A Case Control Study on Risk Factors. PloS ONE, 9, e105214. https://doi.org/10.1371/journal.pone.0105214

[26] Li, D., He, W., Chen, B. and Lv, P. (2017) Primary Drug Resistant Tuberculosis versus Drug-Sensitive Tuberculosis in Non-HIV Infected Patients: Comparisons of CT Findings. PLoS One, 12, e0176354. https://doi.org/10.1371/journal.pone.0176354

[27] Seid, M.A., Ayalew, M.B., Muche, E.A., Gebreyohannes, E.A and Abegaz, T.M. (2018) Drug-Susceptible Tuberculosis Treatment Success and Associated Factors in Ethiopia from 2005-2017: A Systematic Review and Meta-Analysis. BMJ Open, 8, e022111. https://doi.org/10.1136/bmjopen-2018-022111

[28] Alene, K.A., Yi, Z., Viney, K., et al. (2017) Treatment Outcomes of Patients with Multidrug-Resistant and Extensively Drug Resistant Tuberculosis in Hunan Province, China. BMC Infectious Diseases, 17, Article No. 573. https://doi.org/10.1186/s12879-017-2662-8

[29] Wu, B., Zhang, L., Liu, Z., et al. (2017) Drug-Resistant Tuberculosis in Zhejiang Province, China: An Updated Analysis of Time Trends, 1999-2013. Global Health Action, 10, Article: 1293925. https://doi.org/10.1080/16549716.2017.1293925

[30] National Tuberculosis Control Program. Directorate General of Health Services (DGHS), Dhaka, Bangladesh. 2018 Annual Report.

[31] Chowdhury, M.R., Rahman, M.S., Mondal, M.N., Sayem, M.A. and Billah, B. (2015) Social Impact on Stigma Regarding Tuberculosis Hindering Adhere to Treatment: A Cross Sectional Study Carried Out in Tuberculosis Patients at Rajshahi City, Bangladesh. Japanese Journal of Infectious Diseases, 68, 461-466. https://doi.org/10.7883/yoken.JJID.2014.522

[32] Karuniawati, H., Puttra, O.N. and Wikantyasning, E.R. (2019) Impact of Pharmacist Counseling and Leaflet on the Adherence of Pulmonary Tuberculosis Patients Lungs Hospital in Indonesia. Indian Journal of Tuberculosis, 66, 364-369. https://doi.org/10.1016/j.ijtb.2019.02.015

[33] Sinclair, D., Abba, K., Grobler, L. and Sudarsanam, T.D. (2011) Nutritional Supplements for People Being Treated for Active Tuberculosis. Cochrane Database of Systematic Reviews, 9, CD006086. https://doi.org/10.1002/14651858.CD006086.pub3

[34] Kanjee, Z., Amico, K.R., Li, F., Mbolekwa, K., Moll, A.P. and Friedland, G.H. (2012) 
Tuberculosis Infection Control in a High Drug-Resistance Setting in Rural South Africa: Information, Motivation, and Behavioral Skills. Journal of Infection and Public Health, 5, 67-81. https://doi.org/10.1016/j.jiph.2011.10.008

[35] Ullah, I., Javaid, A., Tahir, Z., Ullah, O., Shah, A.A., Hasan, F. and Ayub, N. (2016) Pattern of Drug Resistance and Risk Factors Associated with Development of Drug Resistant Mycobacterium Tuberculosis in Pakistan. Prevalence of Drug Resistance Tuberculosis. PloS ONE, 25, e0147529.

https://doi.org/10.1371/journal.pone.0147529 


\title{
Appendix
}

\author{
Total MDR-TB patient \\ $\mathrm{N}=233$ \\ $\downarrow$
}

Received nutritional support under PMDT$$
\mathrm{N}=233
$$$$
\downarrow
$$

Analyzed for treatment outcomes

Followed nine months treatment regimen

$$
\mathrm{N}=233
$$

MDR-TB with regular BMI data 46

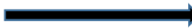

$$
\mathrm{N}=187
$$

Weight measured at regular interval in hospital (in IP) (first four months), $\mathrm{N}=187$

\section{I}

Weight measured at regular interval in community (in CP) (next five months), $\mathrm{N}=187$

$$
\text { I }
$$

Analyzed BMI with age, initial weight, gender and different treatment setting following treatment phases $\mathrm{N}=187$

$\mathrm{IP}=$ Intensive phase of treatment, $\mathrm{CP}=$ Continuation phase of treatment, $\mathrm{MDR}-\mathrm{TB}=$ Multi-drug resistant $\mathrm{TB}$

Figure S1. Diagrammatic representation of sampling protocol. 